\title{
The long-term outcomes and health-related quality of life of patients following blunt thoracic injury: a narrative literature review
}

\author{
Edward Baker ${ }^{1,2^{*}}$ D, Andreas Xyrichis ${ }^{1}$, Christine Norton ${ }^{1}$, Philip Hopkins ${ }^{3}$ and Geraldine Lee
}

\begin{abstract}
Background: Major Trauma remains a leading cause of mortality and morbidity worldwide. Blunt Thoracic Injury (BTI) accounts for $>15 \%$ of United Kingdom (UK) trauma admissions and is consistently associated with respiratory related complications that include pneumonia and respiratory failure. Despite this, it is unclear in current clinical practice how BTI impacts on the recovering trauma patients after discharge from hospital. This study aimed to investigate the state of knowledge on the impact of BTI on the long-term outcomes and health-related quality of life (HRQoL).

Methods: Data were sourced from Ovid MEDLINE, Ovid EMBASE, CINAHL and Science Direct using a pre-defined systematic search strategy. A subsequent hand search of key references was used to identify potentially missed studies. Abstracts were screened for eligibility and inclusion. Fifteen studies met the eligibility criteria and were critically appraised. Data were extracted, analysed and synthesised in categories and sub-categories following a narrative approach.
\end{abstract}

Results: Three major themes were identified from the 15 studies included in this review: (i) physical impact of BTI, (ii) psychological impact of BTI and (iii) socio-economic impact of BTI. The bulk of the available data focused on the physical impact where further sub-themes included: (i) physical functioning, (ii) ongoing unresolved pain, (iii) reduced respiratory function, (iv) thoracic structural integrity. Although there was a substantial difference in the length and method of follow up, there remains a general trend towards physical symptoms improving over time, particularly over the first six months after injury. Despite this, where sequelae continued at six months it remained likely that these would also be present at two years after injury.

Conclusion: The literature review demonstrated that BTI is associated with substantial sequelae that impacts on all aspects of daily functioning. Despite this there remains a paucity of data relating to long term outcomes in the BTI population, especially relating to psychological and socio-economic impact. There is also little consensus on the measures, tools and time-frames used to measure outcomes and HRQoL in this population. The full impact of BTI on this population needs further exploration.

Keywords: Trauma, Rib fractures, Chest trauma, Quality of life, Patient reported outcomes, Injury, Morbidity

\footnotetext{
* Correspondence: edward.e.baker@kcl.ac.uk

${ }^{1}$ Florence Nightingale Faculty of Nursing, Midwifery and Palliative Care, King's

College London, James Clerk Maxwell Building, 57 Waterloo Road, London

SE1 8WA, UK

${ }^{2}$ Emergency Department, King's College Hospital NHS Foundation Trust,

Denmark Hill, London SE5 9RS, UK

Full list of author information is available at the end of the article
}

(c) The Author(s). 2018 Open Access This article is distributed under the terms of the Creative Commons Attribution 4.0 International License (http://creativecommons.org/licenses/by/4.0/), which permits unrestricted use, distribution, and reproduction in any medium, provided you give appropriate credit to the original author(s) and the source, provide a link to the Creative Commons license, and indicate if changes were made. The Creative Commons Public Domain Dedication waiver (http://creativecommons.org/publicdomain/zero/1.0/) applies to the data made available in this article, unless otherwise stated. 


\section{Background}

Major trauma continues to be a leading cause of death for both men and women under the age of 44 years in high-income countries $[1,2]$. Blunt Thoracic Injury (BTI) is characterised by injury that does not involve opening of the chest wall and therefore the severity can vary from minor haematoma to significant injury that compromises thoracic structural integrity [2, 3]. Isolated BTI accounts for over $15 \%$ of UK trauma admissions and is consistently associated with a high level of respiratory-related complications such as pneumonia, respiratory failure and subsequent pulmonary embolism [2, 4-6].

It is often challenging for healthcare professionals (HCP) to comprehend the impact of disease on patients' daily lives [7, 8]. Patient Reported Outcome Measures (PROMs) have been developed to meet these challenges and reduce the gap between clinicians' and patients' understanding of these, therefore focusing care on patients' preference and needs [8]. Despite evidence suggesting that PROMs can improve communication between HCPs and patients whilst promoting patient autonomy and improving patient satisfaction, their use in trauma care requires further development [9-12]. Furthermore, there are very limited trauma specific PROMs available and currently insufficient evidence to fully understand the effectiveness of generic measures in the trauma population [12, 13]. Whilst further investigation of PROMs in trauma care is needed, it is important to investigate how these measures are currently utilised and presented in the literature.

In the general major trauma population, physical injury has been shown to impact on all aspects of quality of life [14-21]. This has resulted in negative changes to physical functioning including ability to sleep, changes in psycho-sexual function and effects on employment, financial status and ability to return to work [20, 22-26]. Despite these documented sequelae, it is unclear in current clinical practice how BTI specifically impacts on the recovering trauma patient and their health-related quality of life (HRQoL) after discharge from hospital [27].

HRQoL is a challenging term to define due to its multi-dimensional nature [28]. It is broadly agreed that HRQoL is the functional effect of a medical problem and its consequent treatment upon the individual and their daily life, involving their perceptions of physical, mental, emotional and social functioning [29]. In those with blunt thoracic injury, the identification of potential variables that have an impact on HRQoL can help determine the effectiveness of interventions, such as analgesic modes or evidence-based care pathways, for patients with blunt thoracic injury [12, 30-32].

\section{Aim of the study}

The aim of this literature review was to identify and synthesise the current state of evidence related to the long-term outcomes that are associated with BTI. Specific objectives of this review include:

- Identify the impact of BTI on the long-term functional outcomes of major trauma patients;

- Explore which outcome measures have been used in previous research to measure these long-term functional outcomes; and

- Identify which physical, psychological and socioeconomic sequelae impact on the long-term functional outcomes and HRQoL of patients with BTI.

\section{Method}

A narrative review methodology was used to identify and synthesise the literature. This review used a recognised method of planning the search, critically selecting relevant papers, identifying themes through in-depth analysis and then applying these findings in the context of this study [33].

Five databases were used to identify the studies included in this literature review: Ovid Medline, Ovid EMBASE, Cumulative Index to Nursing and Allied Health (CINAHL) and Science Direct. All databases were searched from inception to September 2017. The search was developed using a combination of search terms: 'trauma, 'injury, 'patient reported outcomes', 'long term outcomes' and 'impact'. Key papers were also hand searched for additional unidentified studies. At this stage all levels of evidence were deemed eligble for inclusion in this review.

Data extraction from each study was standardised using a predetermined table and focused on: research design, sample characteristics and size, outcome measures and tools, setting and research methods. As part of the data extraction process, outcome measures used in each study were identified. Included studies were then critically appraised for quality using the relevant assessment tool from the Critical Appraisal Skills Programme (CASP) [34]. The variability in the validity and reliability of the outcome measures and the method of measuring the outcomes are considered in the critical appraisal of the research studies.

\section{Results}

The combined results of the database searches identified 598 published studies. The initial screening by title and study type resulted in the exclusion of 376 studies due to irrelevance to the topic and duplication. The remaining 226 abstracts were obtained for further assessment of relevance and a further 88 studies were excluded for not meeting the eligibility 
criteria. The review of titles and abstracts was undertaken by the primary author (EB) and discussed at team meetings. Studies published in English that were primary quantitative or qualitative research reports investigating long-term outcomes and HRQoL measures after BTI were included. The remaining 138 studies were reviewed in full by EB resulting in the exclusion of a further 124 studies. Justification for the 211 studies which were excluded are as follows: focused on a population that was less than 16 years of age $(n=1)$, focused on outcomes in the non-BTI trauma population $(n=126)$, focused on acute care outcomes $(n=11)$, non-research articles $(n=71)$ or where participants did not require admission to hospital $(n=2)$. Any uncertainty surrounding article inclusion/exclusion was discussed and an agreement reached based on the eligibility criteria. This resulted in 15 studies that met all eligibility criteria for the review and were included in the data analysis and synthesis (Fig. 1).
Table 1 presents a summary of the critical appraisal process. The 15 studies were compared and then synthesised to form emergent and final themes.

The 15 studies included a total of 1923 participants from eight different countries. Of the studies included, 13 were prospective observational studies ( $n=12$ single centre, $\mathrm{n}=1$ multi-centre), one was a Randomised Controlled Trial (RCT) and one study used a qualitative interview design. In nine of the studies, patient outcomes were measured during a single post-discharge follow-up undertaken between 50 days to 12 years after injury. Four studies undertook repeated follow-up of participants through a pre-defined time frame between one-month and two years following BTI. In the quantitative studies included, there was substantial variance in the sample sizes with eight studies recruiting less than 50 participants (range: 10-734). Table 2 reviews the injury characteristics and demographics of participants included.

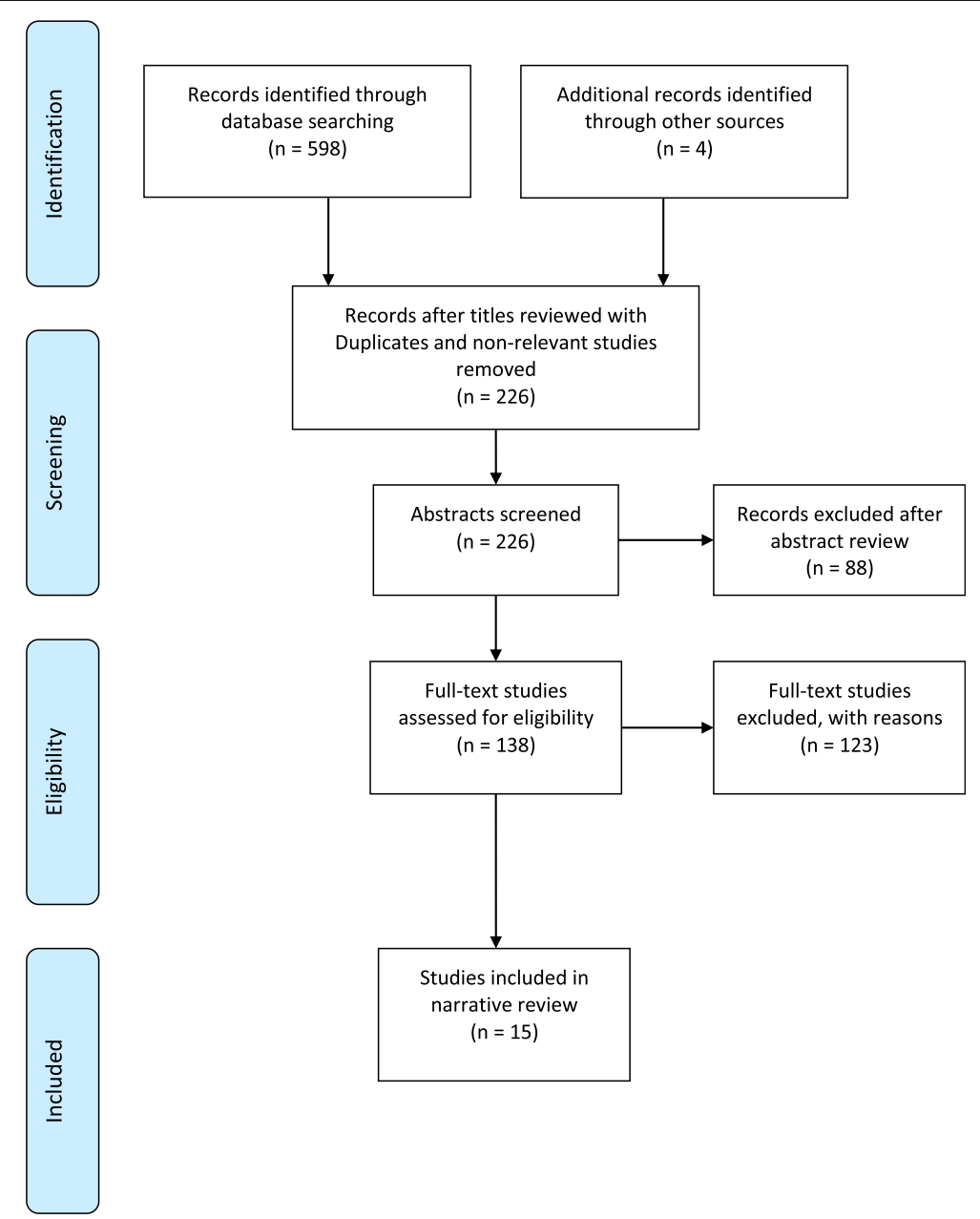

Fig. 1 PRISMA Flow Chart summarising study selection [70] 


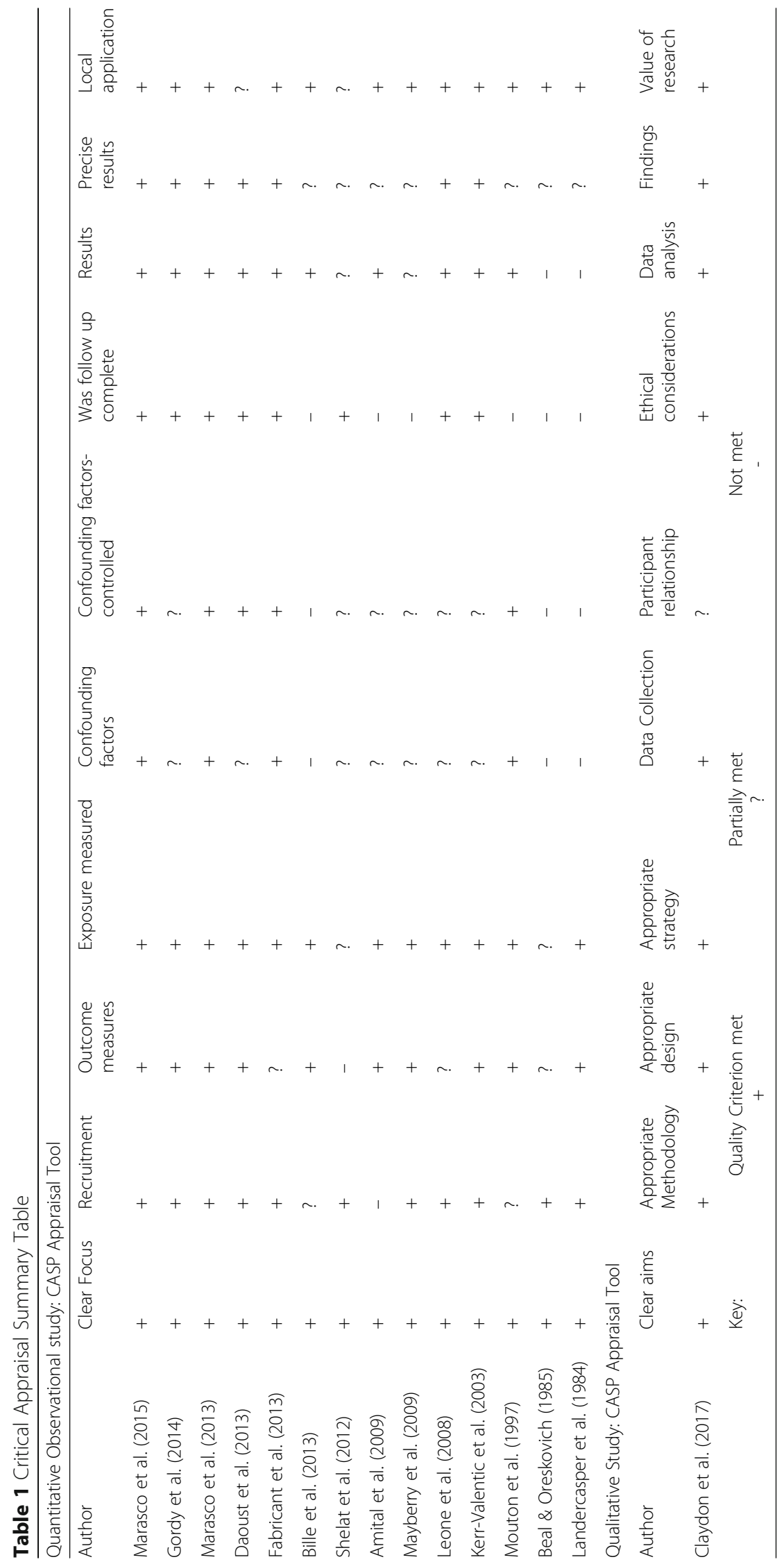




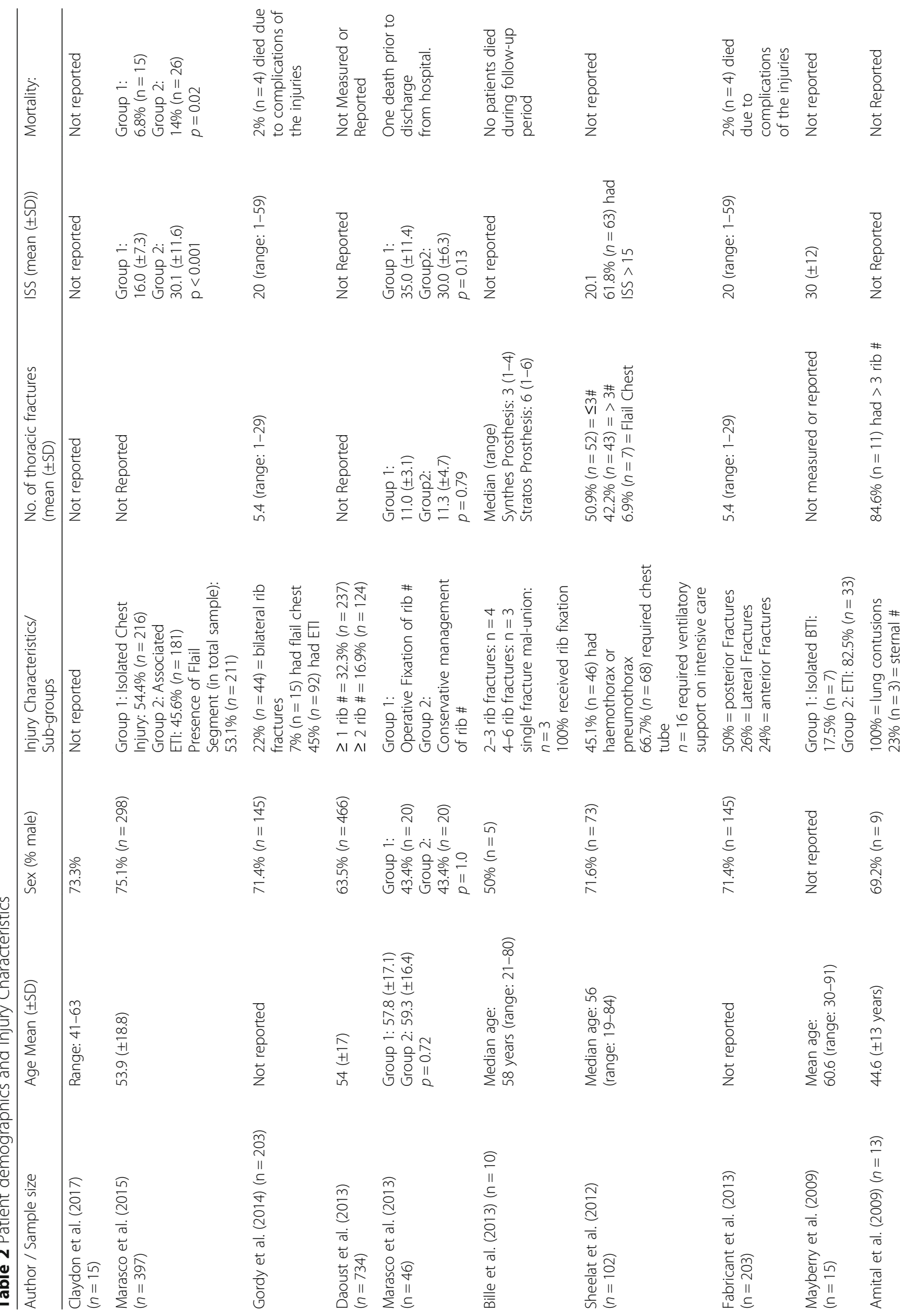




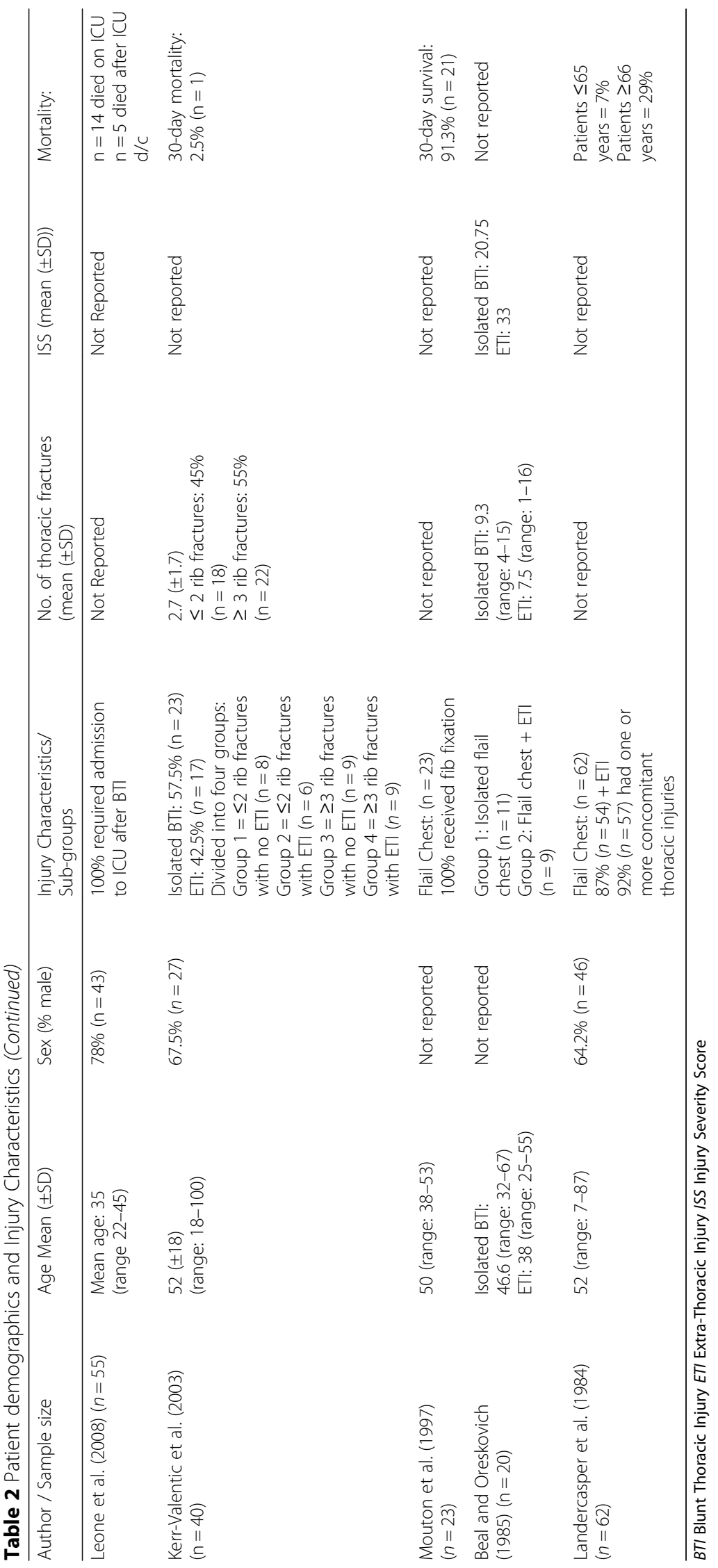


Three overarching themes were identified: i) Physical impact of BTI; ii) Psychological impact of BTI; and, iii) Socio-economic impact of BTI. There are relationships and inter-dependence between each of the three themes and each theme links directly to HRQoL. Table 3 presents a summary of the key findings from studies included in the review.

\section{Physical impact of blunt thoracic injury}

All of the included studies reported on the physical impact of BTI. These studies used different sample populations (i.e. varying injury severity, treatment requirements and presence of extra-thoracic injuries), outcome measures and measurement tools, methodology and follow-up timeframes. Notwithstanding these differences, these studies report that the most seriously injured patients with BTI are not fully recovered from the injuries they sustained after the specific study data collection period. The results of the studies in relation to the physical impact of BTI are presented below under the sub-themes of: (i) pain after BTI, (ii) physical function after BTI, (iii) post injury thoracic deformity, (iv) respiratory function after BTI.

\section{Pain after blunt thoracic injury}

On-going pain after BTI has been identified by 12 out of 15 studies included in this review and was identified as a key outcome measure [35-46].

Visual analogue scale Of these studies, five measured pain using a Visual Analogue Scale (VAS) (Range: 0-10) [35, 36, 38, 39, 45]. Despite the limitations associated with VAS for pain assessment which includes potential for misinterpretation, risk of bias and a poor sensitivity to change; these studies identified on-going pain after BTI. Marasco et al. (2015) identified a mean VAS pain score of 2/10 (range: $0-10$ ) at 6-months post injury and did not identify any statistically significant difference in pain scores reported by participants with isolated thoracic injury and those with associated extra-thoracic injuries at 12 -months (mean 2 (range $0-5$ ) vs. mean 2 (range 0-5) $p=0.35$ ) and 24-months (mean 1 (range 04) vs. mean 0 (range $0-5) p=0.5$ ) after injury [39]. Similarly, Fabricant et al. reported mean VAS score of 3.5 at 1 month after injury despite high opiate usage amongst both participants with isolated and extra-thoracic injuries. When comparing the difference between thoracic pain and pain in other body parts, there was no statistically significant differences at any time point (day 1, 5, $30,120)$ [36]. Furthermore, in a unique prospective observational study using trajectory modelling and VAS pain scoring, Daoust et al. identified pre-morbid smoking (Prevalence Ratio (PR): 1.8 (95\% CI 1.3-2.6) $p=0.0009)$, the presence of two or more rib fractures
(PR: 1.9 [95\% CI 1.3-2.7], $p=0.0004$ ) and initial oxygen saturations of less than 95\% (PR: 1.7 [95\% CI 1.1-2.6], $p=0.03)$ as statistically significant predictors of pain at 90 days after injury [45].

McGill pain questionnaire Three studies measured patients' sensory, affective and subjective experience of pain using the McGill Pain Questionnaire (MPQ) [36, 37, 43]. In the MPQ, an increased score indicates 'worse' outcomes and pain intensity. In a U.S. study $(n=203)$, at 2 months after injury the MPQ Pain Rating Index (PRI) and Present Pain Intensity (PPI) scales were a median of 1 (MPQ range: $0-5$ ) and a mean of $10.6 \pm 10.9$ (PPI range: 0-44) respectively despite $24 \%$ of the sample remaining on opiate analgesic agents [36]. Similarly, Mayberry et al. reported a mean MPQ PRI of $6.7 \pm 2.1$ in their sample [43]. In this study, measurement used only one component from the MPQ and the follow-up was not undertaken at a pre-defined time point after injury which would likely introduce measurement bias into this study. Fabricant et al. and Gordy et al. reported that 59\% $(n=110)$ and 22\% $(n=35)$ respectively reported on-going chest pain and $76 \%(n=142)$ and $53 \%(n=86)$ respectively reported on-going disability associated with this pain at 2 months after injury [36, 37]. In the multivariate analysis showed enrollment MPQ PPI (undertaken during hospital admission) was an independent predictor of prolonged chest pain (Odds Ratio (OR): 1.6: 95\% CI 1.1 to 2.3 ) but no specified injury characteristics predicted ongoing chest pain at 6 months after injury [36].

In a qualitative interview study using Interpretive Phenomenological Analysis (IPA), 14 participants were interviewed about their recovery after BTI between four and nine months post injury [44]. In this study, most participants identified learning to live with debilitating pain as a primary component of learning to cope with the injury itself.

\section{Physical function}

Physical function after BTI was quantified by nine studies included in this review using self-reporting methods [35-40, 42, 43, 47].

HRQoL component outcome measures In both the SF-36 and SF-12 assessment tools, a higher score indicates 'better' outcomes, i.e. better HRQoL. Kerr-Valentic et al. measured the physical function score at one-month after BTI. This study $(n=40)$ compared the mean physical function score with the RAND reference group of chronically ill patients and found scores of 43.8 $( \pm 29.6)$ vs. $70.6( \pm 27.4)$ for the reference group $(p<0.01)$ [35]. This highlights the level of comparative disability experienced by BTI patients at one-month after injury. In a prospective observational study 


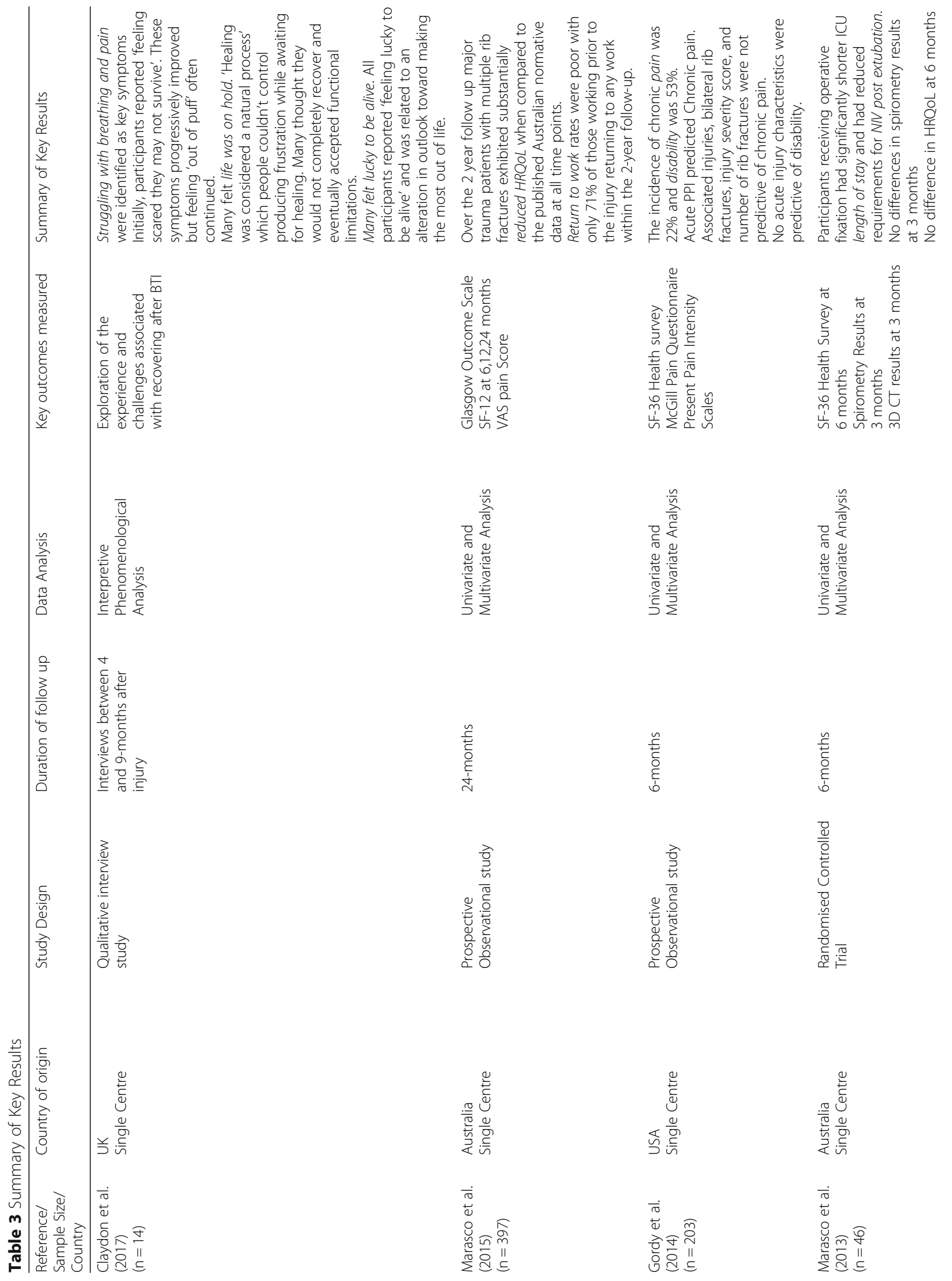




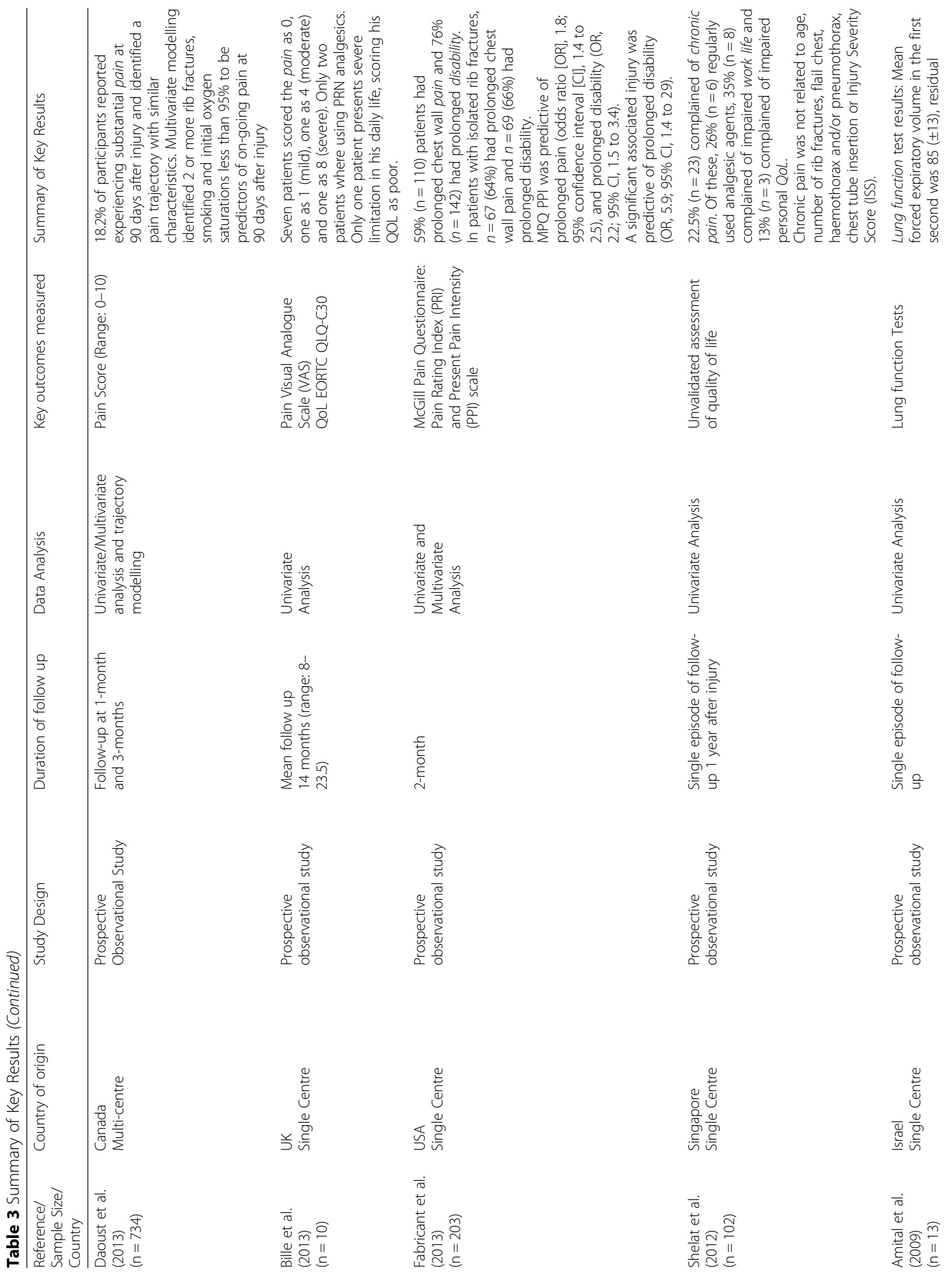




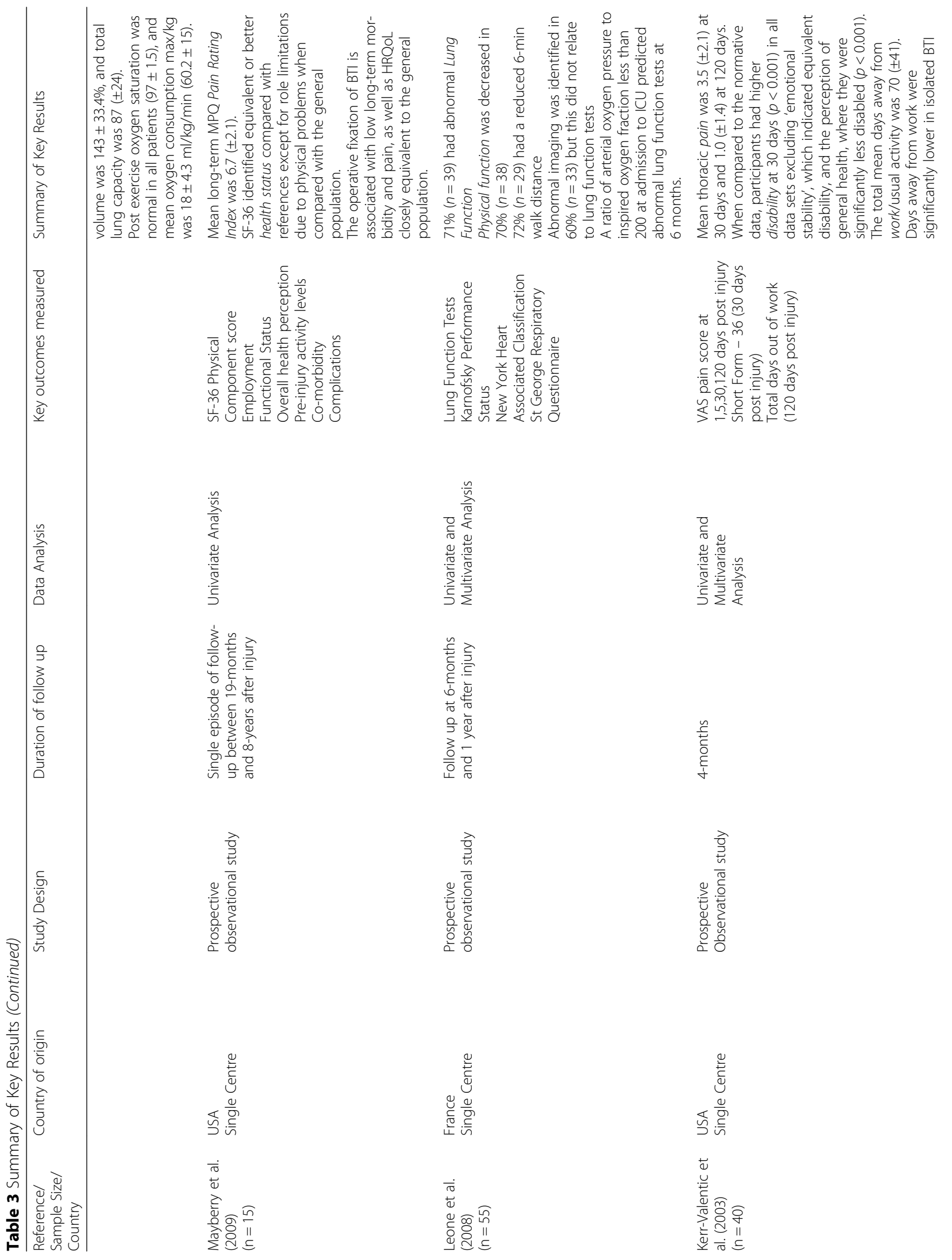




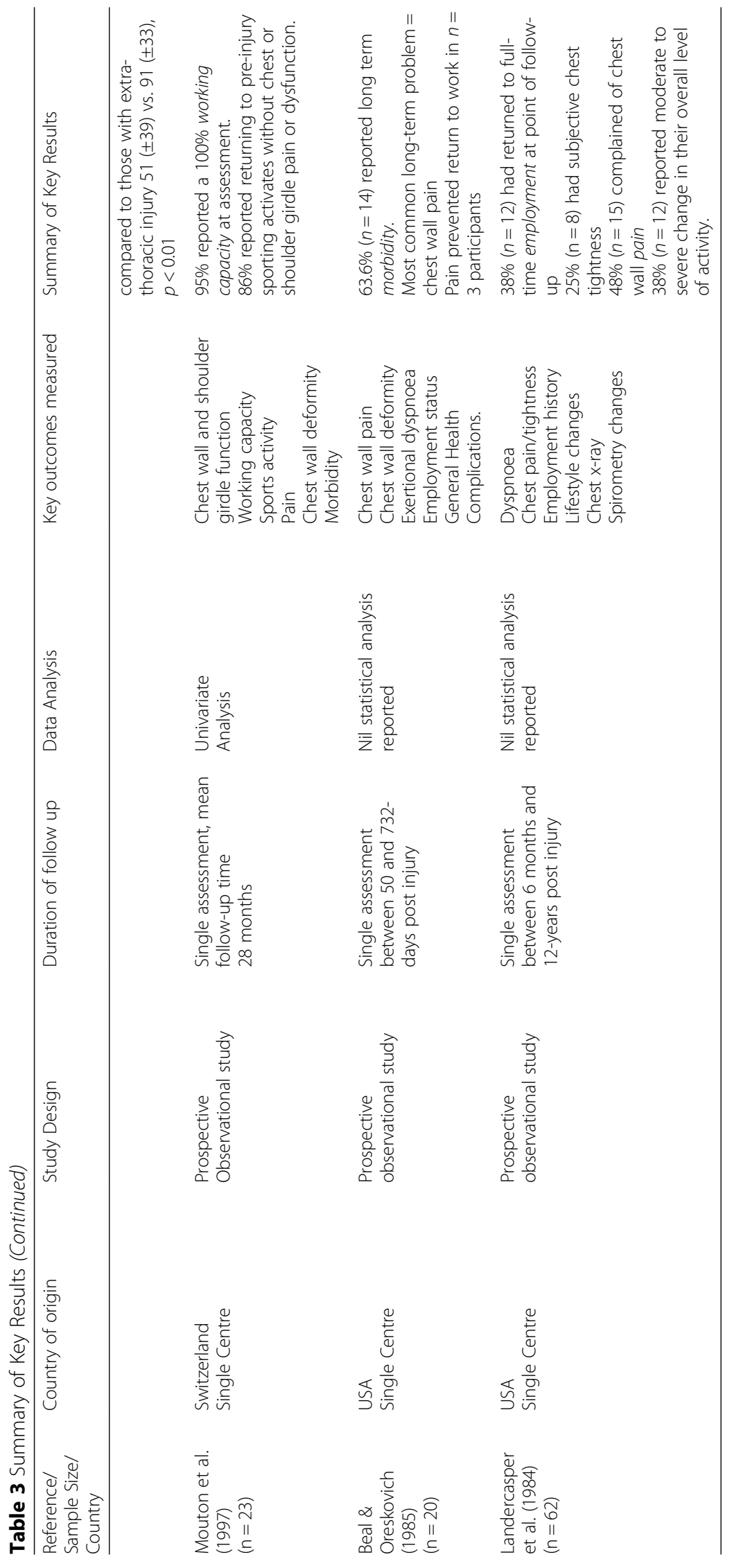


( $n=203)$, Gordy et al. reported the mean physical function score at two-months (48.1), four-months (63.6) and six-months (70.4) but did not include standard deviation for these results and does not include the SF-36 summary component scores for physical and mental health in the univariate or multivariate statistical analysis [37].

At six-months after BTI, two studies by Marasco et al. reported no statistically significant differences in SF-12/ SF-36 Physical Component Score (PCS) $(39.7$ ( \pm 12.6$)$ vs. $37.3( \pm 12.3) p=0.14)$ between those with isolated thoracic injury and those in the multiple trauma group and similarly $(33.6( \pm 9.8)$ vs. $35.2( \pm 10.7) p=0.65)$ between participants receiving operative rib fixation and those receiving conservative management $[39,47]$. When the SF-12 PCS was compared with the Australian normative data, there were significant differences in the PCS with the Australian norms for physical function being significantly higher than the study population with BTI (Australian 2013 published norm: $48.9( \pm 10.2) p<0.0001)$. Similarly, the outcomes reported at both 12 and 24 months were the same with reduced functional ability reported at each timeframe (PCS 12 months v.s. 24 months: $38.6( \pm 0.9)$ v.s. $38.9( \pm 1.0) \mathrm{p}=\mathrm{NS})$ [39].

Other physical function outcome measures One observational study compared long-term outcomes amongst BTI patients after operative fixation $(n=10)$ using two different rib fixation prosthesis (Synthes and Stratos prosthesis). In this study, the EORTC QLQ-C30 questionnaire was used to measure functional outcomes and quality of life despite the tool being developed for use with cancer patients without previous validation in a trauma population [38]. This study reported limited quantitative findings of functional outcomes in both patient groups but reported that the functional scale and symptoms scale outcomes were lower in the Stratos group - this was not statistically significant [38].

\section{Post injury thoracic deformity}

Four studies assessed participants for visible structural changes in the thoracic wall [40-42, 47]. The incidence of chest wall deformity was identified as $21.4 \%(n=3)$ and $26.9 \%(n=7)$ in two studies $[40,41]$. In one study, $46 \%(n=12)$ were unable to expand their chest more than $5 \mathrm{~cm}$ demonstrating significantly reduced respiratory function [40]. These studies link the impact of chest wall deformity with changes in respiratory function in the post injury recovery phase which is discussed below. Furthermore, these data are limited due to the single episode of follow-up undertaken between 50 days and 12 years after injury but identifies a relationship between thoracic deformity, respiratory function and HRQoL.

\section{Respiratory function after blunt thoracic injury}

Optimised respiratory function is understood to be a key variable in the prevention of respiratory complications after BTI. Three studies investigated respiratory function through follow-up chest radiology, physical examination, spirometry including carbon monoxide diffusion, smoking history and subjective and objective dyspnoea assessment $[40,41,48]$. The incidence of post injury dyspnoea was identified as $63 \%(n=20)$ and $29 \%(n=4)$ respectively at a single variable point of follow-up after discharge from hospital [40, 41]. Unfortunately, Beal \& Oreskovich failed to present any specific data on pulmonary function tests preventing further inclusion of results in this review [41]. Similarly, Landercasper et al. reported only the incidence of respiratory abnormality with $57 \%(n=12)$ of the sample producing abnormal spirometry results at a single variable point of follow-up after discharge from hospital. Furthermore, there was a $75 \%$ reduction in participant self-reported smoking in the post injury follow-up (although it is not clear whether this included both those who reduced daily smoking habits and those who quit completely). Interestingly, 27\% $(n=4)$ had lower than normal lung volumes and $100 \%(n=26)$ had abnormalities on chest X-ray consistent with pulmonary fibrosis [40]. Leone et al. identified only a partial pressure of oxygen/fraction of inspired oxygen $(\mathrm{PaO} 2 / \mathrm{FiO} 2)$ ratio of less than 200 on admission as a determinant of prolonged pulmonary complications in a predictive model. Pre-injury status, injury severity, ICU treatments and initial CT findings did not predict impaired pulmonary function [49].

In the qualitative interview study, both pain and difficulty in breathing were identified as a significant challenge that participants struggled to overcome. This important finding further highlights reduced respiratory function after BTI and the impact this has on physical function despite participants reporting that symptoms improved slightly each day [44].

\section{Psychological impact of blunt thoracic injury}

Mental health squelae after BTI was assessed in three of the studies included in this review [37, 39, 47]. These studies have all used the Mental Component Score (MCS) of the SF-36 or SF-12 to measure the impact of psychological sequelae on HRQoL after BTI. Marasco et al. lead two studies that reported no statistically significant difference in the SF-12 MCS when comparing participants with isolated thoracic injury and those with associated extra-thoracic injuries at 6 months after injury (49.2 (SE 12.4) vs. 48.3 (SE 14.4) $p=0.61$ ) and between participants who received operative rib fixation and those who were managed conservatively (45.1 (SE 13.8) vs. 45.2 (SE 9.3) $p=0.98)[39,47]$.There was a statistically significant difference in SF-12 MCS when 
compared with the Australian norm: SF-12 MCS was significantly higher than the collective participants of this study (Australian 2013 published norms: 52.4 (SE 8.8) $p<0.0001$ ) [39]. This study also identified that older patients (over 55 years) had significantly better SF-12 MCS scores (50.9 (SE 1.1) vs. 47.1 (SE 1.0) $p=0.01$ ) and female participants had significantly lower SF-12 MCS than men (35.0 (SE 1.5) vs. 41.2 (SE 0.8) $p<0.001$ ). There was no statistically significant difference in the outcomes of the SF-12 MCS at six-months, 12-months or 24-months after injury (48.8 (SE 0.9) vs. 49.3 (SE 0.9) vs. 48.9 (SE 1.0) $p=0.86$ ) [39]. This study surmises that the better psychological outcomes in patients over 55 years was associated with a greater ability to accept physical disability in older age, although no evidence to support this was presented. Similarly, Gordy et al. presented the SF-36 mental health scores at two-months, four-months and six-months after injury $(67.6,72.1$ and 73.3 respectively). Unfortunately, these results were not included in the univariate or multivariate analysis without clear reason and this limited the ability to interpret these findings further [37].

In the qualitative study, Claydon et al. identified a feeling of desperation amongst those recovering from BTI. These participants reported feeling like 'life was on hold' whilst waiting for their injuries to heal and symptoms to subside. It appears that these feelings were exacerbated by a sense of helplessness, like nothing could be done to help them. It is clear from these interviews that this impacted on the participants' ability to regain some semblance of normality whist recovering from their injuries [44]. Although it was not explicitly explored in this study, it is likely that this would negatively impact on the QoL for those involved.

\section{Socio-economic impact of blunt thoracic injury}

Six of the 15 studies reported outcomes relating to lost work days, functional ability to work and capacity to work [35, 39-43]. In these studies, assessment of capacity to return to work and duration of absence from work formed both an assessment of the socio-economic burden of BTI and as a method of further quantifying participant physical functional ability. Mouton et al. identified that $95 \%(n=22)$ of participants could return to full pre-injury employment [42]. The sample in this study included patient with flail segments who had received surgical fixation of fracture. This may suggest that surgical fixation of rib fractures reduced the burden of injury considerably compared to those who have conservative management. Conversely, Marasco et al. reported that $30 \%$ of participants with BTI managed conservatively had not returned to pre-injury employment at two-years after injury [39]. Furthermore, Landercasper et al. found that only $34 \%(n=12)$ of their sample with flail chest who did not receive surgical fixation returned to the same work after injury [40]. This study suggests that those who receive definitive treatment for fractures have improved outcomes and return to work earlier.

Post injury unemployment due to reduced capacity was measured through three studies as $14 \%(n=2)$ [41], $33 \%(n=9)$ [43] and 39\% $(n=11)$ [40]. Returning to work part-time due to associated disability was reported as $11 \%(n=3)$ [43] and 7\% $(n=1)$ [41] of participants and a further $11 \%(\mathrm{n}=3)$ reported inability to work due to decreased functional ability after injury [43]. Furthermore, Kerr-Valentic et al. identified a mean loss of 70 work days (range: 29-111) due to BTI. In this study, those participants with isolated BTI returned to work faster than those with additional extra-thoracic injuries (51 \pm 39 days vs. $91 \pm 33$ days, $p<0.01$ ) respectively [35] (Additional file 1).

\section{Discussion}

There is a strong evidence base relating to the outcomes reported by BTI victims during the acute post injury hospitalisation [50-53]. In contrast to this, the evidence available surrounding long-term outcome after BTI is inadequate due to issues in study methodology, inconsistent follow-up periods and the various outcome measures used in the included studies. Furthermore, in the general trauma population there is evidence suggesting that injury has a long-term impact on function state, mental health, HRQoL and return to a productive work life $[26,32,54]$. Patients with BTI present a further complexity in clinical practice because of the high level of underlying organ injury, associated pain and respiratory complications such as pneumonia $[2,52,55,56]$. Although outcomes are described in the literature, these have not been previously attributed to specific BTI injury patterns [54].

Indicators of injury severity have been identified as a key predictor of negative long-term outcomes [39]. Flail chest itself has been identified as an indicator of severe injury to the thorax $[36,57]$. Patients with flail chest were investigated in six studies [36, 38, 40-42, 47]. Of these, four studies reported using operative fixation of rib fracture for definitive management of flail chest $[38,42,43,47]$. The remaining studies included in this review included participants with varying numbers of rib and sternal fractures (range: 1-16 thoracic fractures) suggesting a substantial difference in injury severity between participants and study populations [35-37, 39, 41]. This difference in the number of rib fractures requires careful consideration in the integration of the results of these studies to prevent bias and over estimation of the impact of the injury on functional status. Furthermore, four studies included in the review compared the long-term outcomes of patients with isolated 
thoracic injury with those who had associated extra-thoracic injuries [35, 39, 41, 43]. Whilst this provides a greater insight into the specific outcomes of these groups, there is added complexity in the assessment of injury severity amongst those with isolated thoracic injury and those with associated extra-thoracic injury [58]. This is likely to be a result of traditional methods of measuring injury severity being less responsive to patients with isolated BTI, potentially leading to under-estimation of morbidity and mortality.

The review also found inconsistent use of outcome measures in current studies. The measures that have been used are often not robust (e.g. 4 point Likert Scale) or do not have proven reliability and validity with physically injured patients (e.g. EORTC QLQ-c30). This finding is supported by Hoffmann et al. who highlighted the current limitations of using generic outcome measurements (e.g. SF-36) in the trauma population. This often results in health outcomes that are not comprehensively explored through the tools available [12]. This highlights the need for a trauma specific outcomes measure that is valid and reliable, specifically for trauma patients [12, 13, 59, 60].

The rich data reported by Claydon et al. from the qualitative interview study demonstrates how qualitative research can add to the knowledge surrounding outcome measures in a specific population [44]. This highlights that qualitative research has an important role and can provide a unique and critical contribution to health outcomes research [61]. The literature included in this review was predominately quantitative in nature. Despite this, there is a general agreement between the findings in both the quantitative studies and the one qualitative study. Further qualitative studies will allow a greater understanding of the patient experience of recovering after BTI and exploration of which outcomes are meaningful of patients.

There was inconsistency in the follow-up timeframes used by studies. Nine studies measured outcomes at a single time point which varied from 50 days to 12 years after injury [38, 41-43, 45-49], whilst four studies used longitudinal follow-up over a predefined timeframe [35-37, 39]. Apart from the obvious challenges associated with synthesising the data from studies undertaken over differing timeframes, Gabbe et al. highlights the importance of careful consideration of timeframes for health-outcomes studies in trauma research [27]. Furthermore, there was variation in recovery rates for certain sub-groups highlighting the need for reflection on both the outcome measures of interest and the specific population being studied [27]. This shows how a more standardised approach to trauma health outcomes research could result in a more robust repository of knowledge in the future.
Although the extended interval between injury and return to work is indicated in these studies, they have not comprehensively measured the socio-economic impact of BTI [62, 63]. There are potentially confounding variables that have not been measured that may influence a patient's return to employment including: socio-economic status, physical demands of role, duration at present job, associated work-related benefits, role flexibility, job satisfaction and individual's motivation to work $[62,64]$. Similarly, it is important to consider the impact of differing levels of social support and compensation/legal practices seen in the countries where the research was conducted, as this could influence a participant's motivation to return after injury [65-69]. Furthermore, variables including pre-injury health status, alcohol and illicit substance misuse behaviours are also likely to impact on the socio-economic impact of BTI [62]. These suggest that further research is required to fully understand the variables contributing to the socio-economic burden of BTI.

\section{Limitations}

In this narrative review, every effort was made to undertake comprehensive searches using systematic and thorough methods. All papers that were identified and available were retrieved and assessed against the eligibility criteria which included both qualitative and quantitative studies. Since there was obvious hetrogeniety in the variables, outcome measures and patient samples used in the studies included, it was not within the scope of this review to undertake a synthesised quantitative analysis. Despite this, it offers a topical investigation of current evidence surrounding the long-term outcomes for patients with BTI that has hitherto been missing from the international literature.

\section{Conclusion}

The review has highlighted that more robust research is necessary to isolate the true effect of BTI on the individuals involved and their families. Developing a greater understanding of the negative impact of BTI will benefit both the patient, through easier access to interventions, and could also decrease the associated implications on the wider society. The evidence included in this review identified the need for clinical staff to consider the long-term outcomes of trauma patients when planning care and assessing ongoing care needs beyond the acute hospital admission. This transition from measuring traditional trauma outcomes to a more functional assessment is essential to the ongoing progression of the major trauma system throughout high-income countries. A reliable method for assessing functional outcomes in trauma is key to the measurement of the effectiveness of trauma care. This could lead to the development of a 
more responsive and predictive care pathway that aims to identify risk of long-term sequelae and reduce the persistent disability and burden of BTI.

\section{Additional file}

Additional file 1: Table S1 Results of Included studies. (DOCX $32 \mathrm{~kb}$ )

\section{Abbreviations}

BTI: Blunt Thoracic Injury; CASP: Critical Appraisal Skills Programme; CINAHL: Cumulative Index to Nursing and Allied Health; CT: Computerised Tomography; ED: Emergency Department; EORTC: European Organisation for Research and Treatment of Cancer; ETI: Extra-Thoracic Injury; HCP: Health Care Professional; HEE: Health Education England; HRQoL: Health-Related Quality of Life; ICU: Intensive Care Unit; IPA: Interpretative Phenomenological Analysis; ISS: Injury Severity Score; MCS: Mental Component Score; MPQ: McGill Pain Questionnaire; NIHR: National Institute for Health Research; NIV: Non-Invasive Ventilation; PCS: Physical Component Score; PPI: Present Pain Index; PRI: Pain Rating Index; PRISMA: Preferred Reporting Items for Systematic Reviews and Meta-Analysis; PROMs: Patient Reported Outcome Measures; QoL: Quality of Life; RCT: Randomised Controlled Trial; SD: Standard Deviation; SE: Standard Error; SF-12: Short Form - 12 Health questionnaire; SF-36: Short Form - 36 Health questionnaire; TOP: Trauma Outcome Profile; UK: United Kingdom; VAS: Visual Analogue Scale

\section{Funding}

Health Education England (HEE) \& National Institute of Health Research (NIHR) through a Clinical Doctoral Research Fellowship at King's College London, UK.

\section{Authors' contributions}

$E B, G L, A X$ and $C N$ conceived this Literature Review, designed the study and protocol. GL, AX, CN and PH are EB's academic supervisors at King's College London. Data collection and analysis was undertaken primarily by EB. EB undertook the initial draft of the manuscript, and GL, AX, CN and PH contributed substantially to subsequent drafts and revisions. EB takes responsibility for the paper as a whole. All authors read and approved the final manuscript.

\section{Authors' information}

EB is a current PhD student at King's College London. GL is EB's Primary PhD supervisor. AX, CN and PH are also members of EB's PhD supervisory team at King's College London.

\section{Ethics approval and consent to participate}

Not applicable.

\section{Consent for publication}

Not applicable.

\section{Competing interests}

The Authors declare that they have not competing interests.

\section{Publisher's Note}

Springer Nature remains neutral with regard to jurisdictional claims in published maps and institutional affiliations.

\section{Author details}

${ }^{1}$ Florence Nightingale Faculty of Nursing, Midwifery and Palliative Care, King's College London, James Clerk Maxwell Building, 57 Waterloo Road, London SE1 8WA, UK. Emergency Department, King's College Hospital NHS Foundation Trust, Denmark Hill, London SE5 9RS, UK. ${ }^{3}$ Department of Intensive Care Medicine, King's College Hospital NHS Foundation Trust, Denmark Hill, London SE5 9RS, UK.
Received: 1 May 2018 Accepted: 1 August 2018

Published online: 17 August 2018

\section{References}

1. Willenberg L, Curtis K, Taylor C, Jan S, Glass P, Myburgh J. The variation of acute treatment costs of trauma in high-income countries. BMC Health Serv Res. 2012:12:267.

2. Baker EJ, Lee GA. A retrospective observational study examining the effect of thoracic epidural and patient controlled analgesia on short-term outcomes in blunt thoracic trauma injuries. Medicine (Baltimore). 2016;95: e2374.

3. Keel M, Trentz O. Pathophysiology of polytrauma. Injury. 2005;36:691-709.

4. Battle $C E$, Hutchings $H$, James $K$, Evans PA. The risk factors for the development of complications during the recovery phase following blunt chest wall trauma: a retrospective study. Injury. 2013:44:1171-6.

5. Battle $C E$, Hutchings $H$, Evans PA. Risk factors that predict mortality in patients with blunt chest wall trauma: a systematic review and metaanalysis. Injury. 2012;43:8-17.

6. Rock P, Rich PB. Postoperative pulmonary complications. Curr Opin Anaesthesiol. 2003;16:123-31.

7. Nelson E, Conger B, Douglass R, Gephart D, Kirk J, Page R, Clark A, Johnson K, Stone K, Wasson J, Zubkoff M. Functional health status levels of primary care patients. JAMA. 1983;249:3331-8

8. Nelson EC, Eftimovska E, Lind C, Hager A, Wasson JH, Lindblad S. Patient reported outcome measures in practice. BMJ. 2015;350:g7818.

9. Marshall S, Haywood K, Fitzpatrick R. Impact of patient-reported outcome measures on routine practice: a structured review. J Eval Clin Pract. 2006;12:559-68.

10. Valderas JM, Kotzeva A, Espallargues M, Guyatt G, Ferrans CE, Halyard MY, Revicki DA, Symonds T, Parada A, Alonso J. The impact of measuring patient-reported outcomes in clinical practice: a systematic review of the literature. Qual Life Res. 2008;17:179-93.

11. Santana MJ, Feeny D. Framework to assess the effects of using patientreported outcome measures in chronic care management. Qual Life Res. 2014:23:1505-13.

12. Hoffman K, Cole E, Playford ED, Grill E, Soberg HL, Brohi K. Health outcome after major trauma: what are we measuring? PLoS One. 2014;9:e103082.

13. Attenberger C, Amsler F, Gross T. Clinical evaluation of the trauma outcome profile (TOP) in the longer-term follow-up of polytrauma patients. Injury. 2012;43:1566-74.

14. Zwingmann J, Hagelschuer P, Langenmair E, Bode G, Herget G, Südkamp NP, Hammer T. Lower health-related quality of life in Polytrauma patients: long-term follow-up after over 5 years. Medicine (Baltimore). 2016;95:e3515.

15. van Delft-Schreurs CC, van Bergen JJ, de Jongh MA, van de Sande P, Verhofstad MH, de Vries J. Quality of life in severely injured patients depends on psychosocial factors rather than on severity or type of injury. Injury. 2014:45:320-6.

16. Ulvik A, Kvåle R, Wentzel-Larsen T, Flaatten H. Quality of life 2-7 years after major trauma. Acta Anaesthesiol Scand. 2008;52:195-201.

17. Ringburg AN, Polinder S, van lerland MC, Steyerberg EW, van Lieshout EM, Patka P, van Beeck EF, Schipper IB. Prevalence and prognostic factors of disability after major trauma. J Trauma. 2011;70:916-22.

18. Rainer TH, Yeung JH, Cheung SK, Yuen YK, Poon WS, Ho HF, Kam CW, Cattermole GN, Chang A, So FL, Graham CA. Assessment of quality of life and functional outcome in patients sustaining moderate and major trauma: a multicentre, prospective cohort study. Injury. 2014;45:902-9.

19. Nathens $A B$. Life after discharge following major injury: expanding our notion of quality in trauma care. Ann Surg. 2016;263:633-5.

20. Wiseman T, Foster K, Curtis K. Mental health following traumatic physical injury: an integrative literature review. Injury. 2013;44:1383-90.

21. Wiseman TA, Curtis K, Lam M, Foster K. Incidence of depression, anxiety and stress following traumatic injury: a longitudinal study. Scand J Trauma Resusc Emerg Med. 2015;23:29.

22. Aitken LM, Chaboyer W, Kendall E, Burmeister E. Health status after traumatic injury. J Trauma Acute Care Surg. 2012;72:1702-8.

23. de Jongh MA, Kruithof N, Gosens T, van de Ree $\mathrm{CL}$, de Munter L, Brouwers L, Polinder S, Lansink KW. BIOS-group: prevalence, recovery patterns and predictors of quality of life and costs after non-fatal injury: the Brabant injury outcome surveillance (BIOS) study. Inj Prev. 2017;23:59.

24. Dinh MM, Cornwall K, Bein KJ, Gabbe BJ, Tomes BA, Ivers R. Health status and return to work in trauma patients at 3 and 6 months post- 
discharge: an Australian major trauma Centre study. Eur J Trauma Emerg Surg. 2016;42:483-90

25. Folkard SS, Bloomfield TD, Page PR, Wilson D, Ricketts DM, Rogers BA. Factors affecting planned return to work after trauma: a prospective descriptive qualitative and quantitative study. Injury. 2016;47:2664-70.

26. Gabbe BJ, Simpson PM, Harrison JE, Lyons RA, Ameratunga S, Ponsford J, Fitzgerald M, Judson R, Collie A, Cameron PA. Return to work and functional outcomes after major trauma: who recovers, when, and how well? Ann Surg. 2016;263:623-32.

27. Gabbe BJ, Simpson PM, Sutherland AM, Wolfe R, Lyons RA, Cameron PA. Evaluating time points for measuring recovery after major trauma in adults. Ann Surg. 2013;257:166-72.

28. Bowling A. Measuring Disease. 2nd ed. Buckingham: Open University Press; 2001.

29. Innocenti F, Del Taglia B, Coppa A, Trausi F, Conti A, Zanobetti M, Pini R. Quality of life after mild to moderate trauma. Injury. 2015;46:902-8.

30. Flanagan S, Damery S, Combes $\mathrm{G}$. The effectiveness of integrated care interventions in improving patient quality of life (QoL) for patients with chronic conditions. An overview of the systematic review evidence. Health Qual Life Outcomes. 2017:15:188.

31. Anderson K, Burckhardt C. Conceptualisation and measurement of quality of life as an outcome variable for health care intervention and research. J Adv Nurs. 1999;29:9.

32. Dimopoulou I, Anthi A, Mastora Z, Theodorakopoulou M, Konstandinidis A, Evangelou E, Mandragos K, Roussos C. Health-related quality of life and disability in survivors of multiple trauma one year after intensive care unit discharge. Am J Phys Med Rehabil. 2004;83:171-6.

33. Beecroft C, Rees A, Booth A. Finding the Evidence. In: Gerrish K, Lacey A, editors. The Research Process in Nursing. 5th ed. Oxford: Blackwell Publishing; 2007. p. 90-106

34. CASP Qualitative Research Checklist. http://www.casp-uk.net/casp-toolschecklists

35. Kerr-Valentic MA, Arthur M, Mullins RJ, Pearson TE, Mayberry JC. Rib fracture pain and disability: can we do better? J Trauma. 2003;54:1058-63. discussion 1063-1054

36. Fabricant L, Ham B, Mullins R, Mayberry J. Prolonged pain and disability are common after rib fractures. Am J Surg. 2013;205:511-5. discusssion 515-516

37. Gordy S, Fabricant L, Ham B, Mullins R, Mayberry J. The contribution of rib fractures to chronic pain and disability. Am J Surg. 2014;207:659-62. discussion 662-653

38. Billè A, Okiror L, Campbell A, Simons J, Routledge T. Evaluation of long-term results and quality of life in patients who underwent rib fixation with titanium devices after trauma. Gen Thorac Cardiovasc Surg. 2013;61:345-9.

39. Marasco S, Lee G, Summerhayes R, Fitzgerald M, Bailey M. Quality of life after major trauma with multiple rib fractures. Injury. 2015:46:61-5.

40. Landercasper J, Cogbill TH, Lindesmith LA. Long-term disability after flail chest injury. J Trauma. 1984;24:410-4.

41. Beal SL, Oreskovich MR. Long-term disability associated with flail chest injury. Am J Surg. 1985;150:324-6.

42. Mouton W, Lardinois D, Furrer M, Regli B, Ris HB. Long-term follow-up of patients with operative stabilisation of a flail chest. Thorac Cardiovasc Surg. 1997:45:242-4

43. Mayberry JC, Kroeker AD, Ham LB, Mullins RJ, Trunkey DD. Long-term morbidity, pain, and disability after repair of severe chest wall injuries. Am Surg. 2009;75:389-94.

44. Claydon J, Maniatopoulos G, Robinson L, Fearon P. Challenges experienced during rehabilitation after traumatic multiple rib fractures: a qualitative study. Disabil Rehabil. 2017:1-10.

45. Daoust R, Emond M, Bergeron E, LeSage N, Camden S, Guimont C, Vanier L, Chauny JM. Risk factors of significant pain syndrome 90 days after minor thoracic injury: trajectory analysis. Acad Emerg Med. 2013;20:1139-45.

46. Shelat VG, Eileen S, John L, Teo LT, Vijayan A, Chiu MT. Chronic pain and its impact on quality of life following a traumatic rib fracture. Eur J Trauma Emerg Surg. 2012;38:451-5.

47. Marasco SF, Davies AR, Cooper J, Varma D, Bennett V, Nevill R, Lee G, Bailey $M$, Fitzgerald M. Prospective randomized controlled trial of operative rib fixation in traumatic flail chest. J Am Coll Surg. 2013;216:924-32.

48. Amital A, Shitrit D, Fox BD, Raviv Y, Fuks L, Terner I, Kramer MR. Long-term pulmonary function after recovery from pulmonary contusion due to blunt chest trauma. Isr Med Assoc J. 2009;11:673-6.
49. Leone M, Brégeon F, Antonini F, Chaumoître K, Charvet A, Ban LH, Jammes Y, Albanèse J, Martin C. Long-term outcome in chest trauma. Anesthesiology. 2008;109:864-71.

50. Battle CE, Evans PA. Predictors of mortality in patients with flail chest: a systematic review. Emerg Med J. 2015;32:961-5.

51. Bederman SS, Murnaghan O, Malempati H, Lansang E, Wilkinson M, Johnston E, Bronstein Y, Finkelstein JA, Yee AJ. In-hospital mortality and surgical utilization in severely polytraumatized patients with and without spinal injury. J Trauma. 2011;71:E71-8.

52. Holcomb JB, McMullin NR, Kozar RA, Lygas MH, Moore FA. Morbidity from rib fractures increases after age 45. J Am Coll Surg. 2003:196:549-55.

53. Lotfipour S, Kaku SK, Vaca FE, Patel C, Anderson CL, Ahmed SS, Menchine MD. Factors associated with complications in older adults with isolated blunt chest trauma. West J Emerg Med. 2009;10:79-84.

54. Senn-Reeves JN, Staffileno BA. Long-term outcomes after blunt injury to the boney thorax: an integrative literature review. J Trauma Nurs. 2013;20:56-64. quiz 65-56

55. Bulger EM, Arneson MA, Mock CN, Jurkovich GJ. Rib fractures in the elderly. J Trauma. 2000;48:1040-6. discussion 1046-1047

56. Bergeron E, Lavoie A, Clas D, Moore L, Ratte S, Tetreault S, Lemaire J, Martin M. Elderly trauma patients with rib fractures are at greater risk of death and pneumonia. J Trauma. 2003:54:478-85.

57. Uchida K, Nishimura T, Takesada H, Morioka T, Hagawa N, Yamamoto T, Kaga S, Terada T, Shinyama N, Yamamoto H, Mizobata Y. Evaluation of efficacy and indications of surgical fixation for multiple rib fractures: a propensity-score matched analysis. Eur J Trauma Emerg Surg. 2017:43:541-7.

58. Chawda MN, Hildebrand F, Pape HC, Giannoudis PV. Predicting outcome after multiple trauma: which scoring system? Injury. 2004;35:347-58.

59. Sleat GK, Ardolino AM, Willett KM. Outcome measures in major trauma care: a review of current international trauma registry practice. Emerg Med J. 2011;28:1008-12.

60. Spreadborough S, Radford K, das Nair R, Brooks A, Duffy M. A study of outcomes of patients treated at a UK major trauma Centre for moderate or severe injuries one to three years after injury. Clin Rehabil. 2017;32:410-8. https://doi.org/10.1177/0269215517730862.

61. Curry LA, Nembhard IM, Bradley EH. Qualitative and mixed methods provide unique contributions to outcomes research. Circulation. 2009:119:1442-52.

62. Mackenzie EJ, Morris JA, Jurkovich GJ, Yasui Y, Cushing BM, Burgess AR, DeLateur BJ, McAndrew MP, Swiontkowski MF. Return to work following injury: the role of economic, social, and job-related factors. Am J Public Health. 1998;88:1630-7.

63. Harris IA, Young JM, Rae H, Jalaludin BB, Solomon MJ. Predictors of general health after major trauma. J Trauma. 2008;64:969-74.

64. Clay FJ, Newstead SV, Watson WL, McClure RJ. Determinants of return to work following non life threatening acute orthopaedic trauma: a prospective cohort study. J Rehabil Med. 2010;42:162-9.

65. Elbers NA, Hulst L, Cuijpers P, Akkermans AJ, Bruinvels DJ. Do compensation processes impair mental health? A meta-analysis. Injury. 2013;44:674-83.

66. Elbers NA, Akkermans AJ, Cuijpers P, Bruinvels DJ. Procedural justice and quality of life in compensation processes. Injury. 2013:44:1431-6.

67. Grant GM, O'Donnell ML, Spittal MJ, Creamer M, Studdert DM. Relationship between stressfulness of claiming for injury compensation and long-term recovery: a prospective cohort study. JAMA Psychiatry. 2014;71:446-53.

68. Hou WH, Tsauo JY, Lin CH, Liang HW, Du CL. Worker's compensation and return-to-work following orthopaedic injury to extremities. J Rehabil Med. 2008:40:440-5.

69. Littleton SM, Cameron ID, Poustie SJ, Hughes DC, Robinson BJ, Neeman T, Smith PN. The association of compensation on longer term health status for people with musculoskeletal injuries following road traffic crashes: emergency department inception cohort study. Injury. 2011;42:927-33.

70. Moher D, Liberati A, Tetzlaff J, Altman DG, Group P. Preferred reporting items for systematic reviews and meta-analyses: the PRISMA statement. BMJ. 2009;339:b2535. 